\title{
Manganese Disulfide (Hauerite) and Manganese Ditelluride. Thermal Properties from 5 to $350^{\circ} \mathrm{K}$ and Antiferromagnetic Transitions*
}

\author{
Edgar F. Westrum, Jr. \\ Department of Chemistry, University of Michigan, Ann Arbor, Micligan 48104 \\ AND \\ FredRIK GRфNVOLD \\ Instilute of Inorganic Chemistry, University of Oslo, Blindern, Norway
}

(Received 28 May 1969)

\begin{abstract}
The heat capacities of manganese disulfide and manganese ditelluride were determined by adiabatic calorimetry in the range $5-350^{\circ} \mathrm{K}$. Lambda-type transitions are present in both compounds with maxima at $47.93^{\circ} \mathrm{K}$ for $\mathrm{MnS}_{2}$ and at $83.0^{\circ} \mathrm{K}$ for $\mathrm{MnTe}_{2}$. Entropies, enthalpies, and Gibbs energy function values are calculated and tabulated. At $298.15^{\circ} \mathrm{K}$ they are: $S^{\circ}=23.88 \mathrm{cal} / \mathrm{mole} \cdot{ }^{\circ} \mathrm{K}, H^{\circ}-H_{0}^{\circ}=3384 \mathrm{cal} / \mathrm{mole}$, $-\left[\left(G^{\circ}-H_{0}{ }^{\circ}\right) / T\right]=12.258 \mathrm{cal} / \mathrm{mole} \cdot{ }^{\circ} \mathrm{K}$ for $\mathrm{MnS}_{2}$ and $34.66,4416$, and 19.847 for $\mathrm{MnTe}_{2}$. The clearly cooperative entropy increments are only $0.71 \mathrm{cal} / \mathrm{mole} \cdot{ }^{\circ} \mathrm{K}$ for $\mathrm{MnS}_{2}$ and 0.80 for $\mathrm{MnTe}_{2}$. Available magnetic susceptibility data are interpreted in terms of zero-field splitting of the ${ }^{6} S_{5 / 2}$ state of the manganese $3 d^{5}$ electrons. The resulting contributions to the heat capacity are evaluated. At $298^{\circ} \mathrm{K}$ the combined $\lambda$-transitional and Schottky contributions to the entropy are 2.6 and $2.4 \mathrm{cal} / \mathrm{mole} \cdot{ }^{\circ} \mathrm{K}$ for $\mathrm{MnS}_{2}$ and $\mathrm{MnTe}_{2}$, respectively.
\end{abstract}

\section{INTRODUCTION}

Manganese disulfide, manganese ditelluride, and manganese diselenide all crystallize with pyrite-type structures $^{1-3}$ in which manganese atoms and the center of the dichalcogenide groups form a sodium chloridelike arrangement. The structure is primitive cubic since the axes of the four $X_{2}$ groups in the unit cell (symmetrical about $0, \frac{1}{2}, 0$, etc.) are parallel to different body diagonals. Each manganese atom is octahedrally coordinated to six chalcogen atoms, while each chalcogen atom is tetrahedrally coordinated to three manganese and one chalcogen atom.

These paramagnetic compounds have five unpaired spins. ${ }^{3,4}$ Antiferromagnetic spin arrangements have been observed by neutron diffraction ${ }^{5,6}$ near $4^{\circ} \mathrm{K}$. The ditelluride was found to exhibit an ordering of the first kind, 7 in which each manganese atom has eight nearest metal neighbors with antiparallel spins and four with parallel spins, while all six second-nearest metal neighbors have spins parallel to the central atom. In the case of the disulfide, the ordering was found to be of the third kind, ${ }^{8}$ which differs from the first kind in the arrangement of the second-nearest neighbors, with only four of them having parallel spins.

The present study was undertaken to gain further insight into the magnetic order-disorder processes by exploring the shape and location of the expected heat capacity maxima. Furthermore, it was anticipated that resolutions of the magnetic contributions to the heat capacities and thermodynamic functions of these compounds would be possible.

\section{EXPERIMENTAL}

\section{Samples}

The manganese disulfide used was in the form of selected naturally occurring hauerite single crystals from Raddusa, Sicily. The crystals were carefully abraded with fine emery paper on all faces to remove oxidation products. Chemical and spectrographic analyses were performed on several crystals. Duplicate chemical analyses by $\mathrm{L}$. Reichen on one crystal indicated an average of $45.93 \% \mathrm{Mn}$ and $53.65 \% \mathrm{~S}$, corresponding to the formula $\mathrm{MnS}_{2.00}$. Determinations on two other crystals by C. O. Ingamels indicated $46.46 \%$ $\mathrm{Mn}$ by weighing as $\mathrm{Mn}_{2} \mathrm{P}_{2} \mathrm{O}_{7}, 52.90 \% \mathrm{~S}$ by the fusion method, and $53.20 \% \mathrm{~S}$ by oxidation to elemental sulfur and sulfate. From these sulfur values, the composition of the sulfide would be deduced as $\mathrm{MnS}_{1.9}$. Independent spectrographic analyses by $\mathrm{W}$. H. Worthring and $\mathrm{N}$. Suhr agreed on the presence of $\mathrm{Sn}(0.05 \%), \mathrm{Fe}$ $(0.03 \%)$, and $\mathrm{Si}(0.02 \%$ and $0.06 \%)$. In the sample further impurities found were as follows: $\mathrm{V}(0.03 \%)$, $\mathrm{Ca}(0.007 \%), \mathrm{Cr}(0.002 \%), \mathrm{Mg}(0.002 \%), \mathrm{Co}$ $(0.001 \%), \mathrm{Ni}(0.001 \%), \mathrm{Nb}(0.0007 \%), \mathrm{Ba}(0.0003 \%)$, Mo $(0.003 \%)$, and $\mathrm{Ti}(0.0003 \%)$. The following elements were also sought but not found: $\mathrm{Ag}, \mathrm{As}, \mathrm{Au}, \mathrm{B}$, $\mathrm{Be}, \mathrm{Bi}, \mathrm{Cd}, \mathrm{Ce}, \mathrm{Ga}, \mathrm{Ge}, \mathrm{Hf}, \mathrm{Hg}$, In, K, La, Li, Na, $\mathrm{Pb}, \mathrm{Pd}, \mathrm{Pt}, \mathrm{Re}, \mathrm{Sb}, \mathrm{Se}, \mathrm{Sr}, \mathrm{Ta}, \mathrm{Te}, \mathrm{Th}, \mathrm{Tl}, \mathrm{U}, \mathrm{W}, \mathrm{Y}$, $\mathrm{Yb}$, and $\mathrm{Zr}$. Se and Te were not detected by x-ray fluorescence.

The lattice constant determined on powdered specimens using a Guinier-type camera with $\mathrm{KCl}\left(a_{20}=\right.$ $6.2919 \AA)$ as an internal standard were $a=6.102 \pm$ $0.001 \AA$, which agrees well with earlier values ${ }^{9}(6.109 \pm$ $0.005 \AA^{*},{ }^{10} 6.107 \pm 0.003 \AA,{ }^{11} 6.1008 \pm 0.0001 \AA$ at $29^{\circ} \mathrm{C},{ }^{12}$ and $6.1016 \mathrm{~A}$ at $20^{\circ} \mathrm{C} .{ }^{13}$

The manganese ditelluride sample was prepared by reacting stoichiometric amounts of manganese and tellurium in an evacuated and sealed quartz tube. The $99.995 \%$ electrolytic manganese supplied by Light Ltd. was reported to contain the following impurities (in $\mathrm{ppm}$ ): $\mathrm{Cu}<1, \mathrm{Mg}<5, \mathrm{Si}<5$. After pickling the metal with $5 \%$ nitric acid in ethyl alcohol, it was degassed in vacuo at $600^{\circ} \mathrm{C}$ for $2 \mathrm{~h}$. The $99.999 \%$ tellurium from the American Smelting and Refining 
Co. contained no impurities detectable by spectrographic methods. The manganese-tellurium mixture was heated at $800^{\circ} \mathrm{C}$ for two days in a double-walled tube and, after cooling to room temperature, the telluride separated from the shattered inner tube. The crushed sample was then annealed at $500^{\circ} \mathrm{C}$ for one week and cooled with the furnace. Chemical analyses of manganese and tellurium indicated $18.35 \%$ manganese and $82.05 \%$ tellurium, which corresponds to a composition $\mathrm{MnTe}_{1.92}$ for the telluride. The amount of $\mathrm{SiO}_{2}$ present in the sample was found to be $0.17 \%$. The lattice constant of the ditelluride was determined to be $a=6.954 \pm 0.001 \AA$, in good agreement with three earlier results $\left(6.957 \pm 0.002 \AA,^{2} 6.951 \pm 0.002 \AA{ }^{14}\right.$ and $\left.6.958 \AA^{15}\right)$.

\section{Cyrogenic Technique}

The heat capacities were measured in the Mark II cryostat ${ }^{16}$ with intermittent heating of the sample under quasiadiabatic conditions. The gold-plated copper calorimeter (laboratory designation W-31) with a capacity of $48 \mathrm{~cm}^{3}$ was surrounded by adiabatic shields provided with electronic control. These consisted of three separate channels of recording circuitry with proportional, rate, and reset actions. Temperature differences between calorimeter and shields were maintained within a millidegree, and thereby the heat exchange was reduced to a magnitude negligible compared with other sources of error. The heat capacity of the calorimeter-heater-thermometer assembly was determined in a separate series of experiments. Small corrections were applied for the differences in the amounts of indium-tin solder for sealing the calorimeter, Apiezon- $T$ grease for thermal contact between calorimeter and heater-thermometer assembly, and helium of about $10 \mathrm{~cm} \mathrm{Hg}$ pressure for improving thermal equilibration between calorimeter and sample. Temperatures determined with the strain-free platinum resistor (laboratory designation A-5) are considered to accord with the thermodynamic temperature scale to within $0.03^{\circ} \mathrm{K}$. All measurements of mass, temperature, resistance,

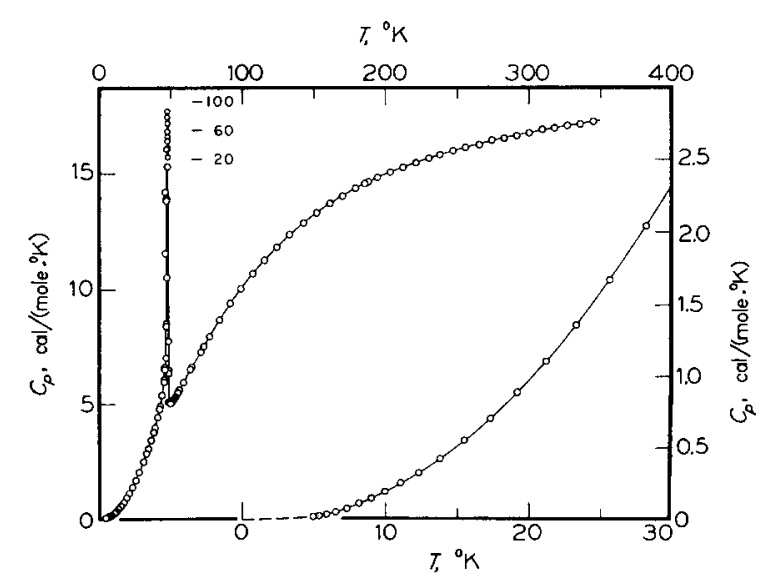

FỊG, 1. Heat capacity of $\mathrm{MnS}_{2}$ (hauerite).

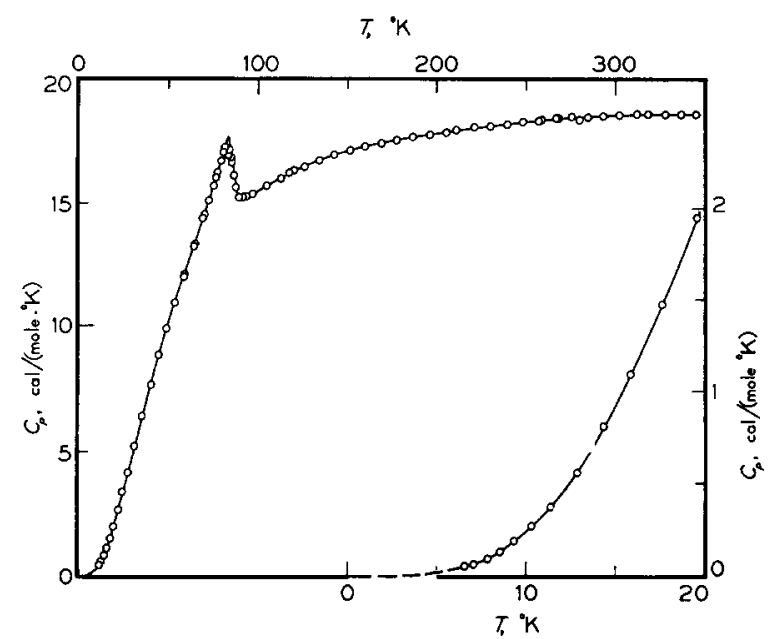

Frg. 2. Heat capacity of $\mathrm{MnTe}_{2}$.

voltage, and time are based upon calibrations or standardizations performed by the U.S. National Bureau of Standards.

\section{RESULTS AND DISCUSSION}

The experimental heat capacity values for manganese disulfide (hauerite) and manganese ditelluride are listed in Table I in chronological sequence at the mean temperatures of the measurements. The data have been corrected for curvature of the heat capacity curve and are given in terms of the defined thermochemical calorie, equal to $4.1840 \mathrm{~J}$, and an ice point of $273.15^{\circ} \mathrm{K}$. The probable errors in the measurements are considered to decrease from about $3 \%$ at $5^{\circ} \mathrm{K}$ to $0.5 \%$ at $10^{\circ} \mathrm{K}$ and to less than $0.1 \%$ above $20^{\circ} \mathrm{K}$.

In both compounds, $\lambda$-type maxima in the heat capacities were observed, the one in hauerite rising rather sharply to a max:mum of $87.26 \mathrm{cal} / \mathrm{mole} \cdot{ }^{\circ} \mathrm{K}$ over a $0.04^{\circ} \mathrm{K}$ interval at $47.93^{\circ} \mathrm{K}$, and the one in manganese ditelluride to a less pronounced maximum of 17.52 $\mathrm{cal} / \mathrm{mole} \cdot{ }^{\circ} \mathrm{K}$ at $83.0^{\circ} \mathrm{K}$. These anomalies are shown in Figs. 1 and 2.

The smoothed heat capacities and thermodynamic functions derived from them by means of a digital computer using a previously described program ${ }^{17}$ are given in Table II for selected temperatures. The thermodynamic functions may be considered reliable to better than $0.1 \%$ above $100^{\circ} \mathrm{K}$.

Enthalpy-type determinations ( $\Delta H$ Run E, 80$113^{\circ} \mathrm{K}$, and $\Delta H$ Run $\mathrm{F}, 113-181^{\circ} \mathrm{K}$ on $\mathrm{MnS}_{2} ; \Delta H$ Run $\mathrm{A}, 54-93^{\circ} \mathrm{K}$, and $\Delta H$ Run $\mathrm{B}, 120-208^{\circ} \mathrm{K}$ on $\mathrm{MnTe}_{2}$ ) noted in Table I provide a test of the heat capacity measurement and integration procedures. The enthalpy increments thus determined accord with corresponding values derived from the smoothed heat capacity curves well within $\pm 0.1 \%$.

In order to evaluate the energy associated with $\lambda$-type transitions in $\mathrm{MnS}_{2}$ the Debye $\theta$ 's calculated from the experimental heat capacities at constant pressure were 
TABLE I. Meat capacity of manganese disulfide (hauerite) and manganese ditelluride. ${ }^{a}$

\begin{tabular}{|c|c|c|c|c|c|c|c|}
\hline$T$ & $C_{p}$ & $T$ & $C_{p}$ & $T$ & $C_{p}$ & $T$ & $C_{\boldsymbol{p}}$ \\
\hline \multicolumn{8}{|c|}{ Maganese disulfide $\mathrm{MnS}_{2}$ (hauerite) $; 1$ mole $=119.07 \mathrm{~g}$} \\
\hline \multicolumn{2}{|c|}{ Series I } & 15.53 & 0.555 & 46.62 & 6.612 & 51.40 & 5.127 \\
\hline 64.99 & 6.653 & 17.34 & 0.709 & 47.01 & 7.055 & 52.41 & 5.248 \\
\hline 71.05 & 7.318 & 19.21 & 0.891 & 47.36 & 8.474 & 53.40 & 5.324 \\
\hline 77.40 & 8.001 & 21.20 & 1.107 & 47.63 & 14.114 & 55.28 & 5.533 \\
\hline 84.23 & 8.725 & 23.32 & 1.364 & 47.77 & 34.74 & 59.23 & 5.985 \\
\hline 91.59 & 9.419 & 25.63 & 1.673 & 47.84 & 78.14 & 64.43 & 6.590 \\
\hline 99.39 & 10.074 & 28.20 & 2.043 & 47.90 & 87.00 & 73.39 & 7.574 \\
\hline 107.43 & 10.707 & 31.08 & 2.496 & 47.94 & 68.93 & \\
\hline 115.56 & 11.291 & 34.38 & 3.066 & 48.00 & 37.32 & & $\Delta H$ Run $\mathrm{E}$ \\
\hline 124.11 & 11.858 & 38.13 & 3.792 & 48.13 & 15.36 & \multirow{2}{*}{\multicolumn{2}{|c|}{$\Delta H$ Run $\mathbf{F}$}} \\
\hline 133.33 & 12.409 & 42.43 & 4.829 & 48.51 & 6.511 & & \\
\hline 142.76 & 12.911 & & \multirow{2}{*}{\multicolumn{2}{|c|}{ Series VI }} & 185.71 & 14.603 \\
\hline 151.99 & 13.350 & \multicolumn{2}{|c|}{$\begin{array}{l}\Delta H \text { Kun } A \\
51.26\end{array}$} & & & 194.63 & 14.862 \\
\hline 161.13 & 13.741 & $\begin{array}{l}51.20 \\
56.34\end{array}$ & 5.176 & & & 203.52 & 15.09 \\
\hline 170.15 & 14.076 & \multirow{2}{*}{\multicolumn{2}{|c|}{ Series III }} & 46.57 & 6.586 & 212.49 & 15.31 \\
\hline 179.18 & 14.399 & & & 47.43 & 10.537 & 221.55 & 15.51 \\
\hline 188.20 & 14.683 & 33.13 & 2.850 & 47.81 & 58.08 & 230.59 & 15.70 \\
\hline \multirow{2}{*}{\multicolumn{2}{|c|}{ Series II }} & 36.32 & 3.432 & 47.89 & 86.88 & 238.09 & 15.85 \\
\hline & & 39.09 & 3.993 & 47.93 & 87.26 & 247.24 & 16.02 \\
\hline 4.98 & 0.020 & 41.02 & 4.435 & 47.97 & 45.65 & 256.32 & 16.17 \\
\hline 5.38 & 0.024 & 42.77 & 4.905 & 48.06 & 23.73 & 265.30 & 16.29 \\
\hline 5.88 & 0.035 & 44.36 & 5.419 & 48.41 & 7.771 & 274.17 & 16.48 \\
\hline 6.54 & 0.051 & \multicolumn{2}{|c|}{$\Delta H t$ Run B } & & 282.99 & 16.54 \\
\hline 7.31 & 0.076 & $\Delta H t \mathrm{R}$ & & \multicolumn{2}{|c|}{ Series VII } & 291.75 & 16.67 \\
\hline 8.15 & 0.111 & 50.12 & 5.031 & \multirow{2}{*}{\multicolumn{2}{|c|}{$\Delta H t$ Run D }} & 300.49 & 16.77 \\
\hline 9.04 & 0.154 & \multicolumn{2}{|c|}{ Series IV } & & & 309.27 & 16.92 \\
\hline 9.99 & 0.205 & \multirow{2}{*}{\multicolumn{2}{|c|}{$\Delta I t$ Run C }} & 49.05 & 5.081 & 318.11 & 17.00 \\
\hline 11.05 & 0.255 & & & 49.58 & 4.992 & 327.03 & 17.08 \\
\hline 12.32 & 0.324 & \multicolumn{2}{|c|}{ Series V } & 50.11 & 5.045 & 336.11 & 17.15 \\
\hline 13.82 & 0.427 & 45.71 & 6.024 & 50.63 & 5.059 & 345.33 & 17.26 \\
\hline Manganese & ide, $\mathrm{Mn}^{\prime}$ & $=310.1$ & & & & & \\
\hline & & 9.31 & 0.182 & & & 96.88 & 15.40 \\
\hline 257.01 & 18.39 & 10.29 & 0.265 & 58.75 & 12.114 & 104.66 & 15.73 \\
\hline 268.21 & 18.48 & 11.40 & 0.370 & 64.36 & 13.370 & 112.46 & 16.05 \\
\hline 278.97 & 18.47 & 12.85 & 0.558 & 69.11 & 14.391 & 120.05 & 16.34 \\
\hline & & 14.36 & 0.805 & 72.60 & 15.16 & $\Delta I I \mathrm{Ru}$ & \\
\hline & & 15.88 & 1.093 & 75.19 & 15.77 & 211.17 & 18.00 \\
\hline 117.57 & 16.27 & 17.63 & 1.472 & 77.33 & 16.29 & 220.88 & 18.12 \\
\hline 125.37 & 16.51 & 19.60 & 1.949 & 79.23 & 16.77 & 230.00 & 18.17 \\
\hline 134.12 & 16.78 & 22.12 & 2.612 & 80.75 & 17.16 & 239.19 & 18.25 \\
\hline 142.68 & 16.99 & 24.79 & 3.343 & 81.74 & 17.34 & 248.46 & 18.33 \\
\hline 151.16 & 17.19 & 27.53 & 4.124 & 82.40 & 17.44 & 257.67 & 18.40 \\
\hline 159.79 & 17.33 & 31.18 & 5.155 & 83.00 & 17.52 & 266.84 & 18.46 \\
\hline 168.73 & 17.50 & 35.62 & 6.416 & 83.60 & 17.41 & 275.94 & 18.53 \\
\hline 177.79 & 17.61 & 40.25 & 7.666 & 84.25 & 17.22 & 285.02 & 18.55 \\
\hline 186.86 & 17.74 & 44.90 & 8.854 & 84.92 & 16.96 & 294.05 & 18.58 \\
\hline 196.02 & 17.84 & 49.28 & 9.930 & 85.59 & 16.66 & 303.12 & 18.62 \\
\hline 205.17 & 17.93 & 53.66 & 10.955 & 86.28 & 16.11 & $\begin{array}{l}303.12 \\
312.27\end{array}$ & $\begin{array}{l}10.02 \\
18.65\end{array}$ \\
\hline & & 58.59 & 12.076 & 87.33 & 15.67 & & \\
\hline & & 64.07 & 13.296 & 89.47 & 15.23 & & \\
\hline 6.58 & 0.041 & 70.03 & 14.587 & 93.92 & 15.27 & 318.84 & 18.64 \\
\hline 7.05 & 0.059 & 76.46 & 16.08 & & & 328.12 & 18.64 \\
\hline 7.85 & 0.088 & 83.46 & 16.98 & & & 337.37 & 18.67 \\
\hline 8.52 & 0.124 & 91.55 & 15.29 & $\Delta I I \mathrm{Ru}$ & & 345.80 & 18.67 \\
\hline
\end{tabular}

${ }^{a}$ Units: calorie, mole, degree Kelvin. 
TABLE II. Thermodynamic properties of manganese disulfide (hauerite) and manganese ditelluride. ${ }^{\mathrm{a}}$

\begin{tabular}{|c|c|c|c|c|c|c|c|c|c|}
\hline$T$ & $C_{p}$ & $S^{\circ}$ & $H^{\circ}-H_{0}^{\circ}$ & $-\left(G^{\circ}-H_{0}^{\circ}\right) / T$ & $T$ & $C_{p}$ & $S^{\circ}$ & $H^{\circ}-H_{0}^{\circ}$ & $-\left(G^{\circ}-H_{0}^{\circ}\right) / T$ \\
\hline \multicolumn{5}{|c|}{ Manganese disulfide, $\mathrm{MnS}_{2}$ (hauerite) $; 1$ mole $=119.07 \mathrm{~g}$} & \multicolumn{5}{|c|}{ Manganese ditelluride, $\mathrm{MnTe}_{2} ; 1$ mole $=310.16 \mathrm{~g}$} \\
\hline 5 & 0.018 & 0.006 & 0.02 & 0.002 & 5 & 0.019 & 0.006 & 0.023 & 0.002 \\
\hline 10 & 0.196 & 0.063 & 0.48 & 0.015 & 10 & 0.228 & 0.060 & 0.471 & 0.013 \\
\hline 15 & 0.513 & 0.198 & 2.20 & 0.051 & 15 & 0.918 & 0.266 & 3.126 & 0.058 \\
\hline 20 & 0.975 & 0.405 & 5.85 & 0.112 & 20 & 2.041 & 0.676 & 10.382 & 0.157 \\
\hline 25 & 1.584 & 0.685 & 12.19 & 0.198 & 25 & 3.403 & 1.275 & 23.94 & 0.318 \\
\hline 30 & 2.322 & 1.037 & 21.90 & 0.307 & 30 & 4.829 & 2.022 & 44.52 & 0.538 \\
\hline 35 & 3.182 & 1.458 & 35.61 & 0.441 & 35 & 6.233 & 2.872 & 72.19 & 0.810 \\
\hline \multirow[t]{2}{*}{40} & 4.195 & 1.947 & 53.97 & 0.598 & 40 & 7.600 & 3.794 & 106.79 & 1.125 \\
\hline & & & & 0.070 & 45 & 8.879 & 4.765 & 148.05 & 1.475 \\
\hline 60 & 6.079 & 4.572 & 183.5 & 1.514 & 50 & 10.099 & 5.764 & 195.5 & 1.854 \\
\hline 70 & 7.212 & 5.595 & 250.0 & 2.024 & 60 & 12.391 & 7.810 & 308.1 & 2.675 \\
\hline 80 & 8.276 & 6.629 & 327.5 & 2.535 & 70 & $\begin{array}{l}12.091 \\
14.588\end{array}$ & 9.886 & $\begin{array}{l}300.1 \\
443.0\end{array}$ & $\begin{array}{l}2.015 \\
3.557\end{array}$ \\
\hline 90 & 9.251 & 7.661 & 415.2 & 3.047 & 80 & 16.97 & 11.984 & 600.5 & 4.476 \\
\hline 100 & 10.129 & 8.682 & 512.2 & 3.560 & 90 & 15.21 & 14.053 & 766.2 & 5.540 \\
\hline 110 & 10.912 & 9.684 & 617.5 & 4.071 & 100 & 15.54 & 15.667 & 919.4 & 6.473 \\
\hline 120 & 11.607 & 10.664 & 730.1 & 4.580 & 110 & 15.96 & 17.169 & 1077.0 & 7.378 \\
\hline 130 & 12.222 & 11.618 & 849.4 & 5.085 & 120 & 16.33 & 18.574 & 1238.5 & 8.253 \\
\hline 140 & 12.767 & 12.544 & 974.4 & 5.585 & 130 & 16.65 & 19.893 & 1403.4 & 9.098 \\
\hline 150 & 13.251 & 13.442 & 1104.5 & 6.079 & 140 & 16.92 & 21.138 & 1571.3 & 9.914 \\
\hline 160 & 13.684 & 14.311 & 1239.2 & 6.566 & 150 & 17.16 & 22.313 & 1741.8 & 10.702 \\
\hline 170 & 14.070 & 15.153 & 1378.0 & 7.047 & 160 & 17.35 & 23.427 & 1914.3 & 11.462 \\
\hline 180 & 14.418 & 15.967 & 1520.5 & 7.520 & 170 & 17.52 & 24.484 & 2088.7 & 12.198 \\
\hline 190 & 14.730 & 16.755 & 1666.2 & 7.985 & 180 & 17.66 & 25.489 & 2264.6 & 12.908 \\
\hline \multirow[t]{2}{*}{200} & 15.01 & 17.518 & 1815.0 & 8.443 & 190 & 17.78 & 26.448 & 2441.8 & 13.596 \\
\hline & 15.26 & 18.256 & 1966.4 & 8.893 & 200 & 17.89 & 27.362 & 2620.1 & 14.262 \\
\hline 220 & 15.49 & 18.972 & 2120.2 & 9.335 & 210 & 17.99 & 28.238 & 2799.5 & 14.906 \\
\hline 230 & 15.70 & 19.665 & 2276.1 & 9.769 & 220 & 18.08 & 29.08 & 2979.9 & 15.53 \\
\hline 240 & 15.89 & 20.337 & 2434.0 & 10.195 & 230 & 18.17 & 29.88 & 3161.1 & 16.14 \\
\hline \multirow[t]{2}{*}{250} & 16.06 & 20.989 & 2593.8 & 10.614 & 240 & 18.25 & 30.66 & 3343.2 & 16.73 \\
\hline & & & & & 250 & 18.33 & 31.40 & 3526.1 & 17.30 \\
\hline 260 & 16.22 & 21.622 & 2755.2 & 11.025 & & & & & \\
\hline 270 & 16.37 & 22.237 & 2918.1 & 11.429 & 260 & 18.41 & 32.12 & 3709.8 & 17.86 \\
\hline 280 & 16.51 & 22.835 & 3082.5 & 11.826 & 270 & 18.47 & 32.82 & 3894.2 & 18.40 \\
\hline 290 & 16.65 & 23.416 & 3248.3 & 12.216 & 280 & 18.53 & 33.49 & 4079.2 & 18.92 \\
\hline \multirow[t]{2}{*}{300} & 16.77 & 23.983 & 3415.4 & 12.598 & 290 & 18.58 & 34.14 & 4264.8 & 19.44 \\
\hline & & & & & 300 & 18.62 & 34.77 & 4450.8 & 19.94 \\
\hline 310 & 16.89 & 24.535 & 3583.7 & 12.975 & 310 & 18.64 & 35.39 & 4637.1 & \\
\hline 320 & 17.01 & 25.073 & 3753.2 & 13.344 & 320 & 18.65 & 35.98 & 4823.5 & $\begin{array}{l}20.43 \\
20.90\end{array}$ \\
\hline 330 & 17.11 & 25.598 & 3923.8 & 13.708 & 330 & 18.65 & 36.55 & 5010.0 & 21.37 \\
\hline 340 & 17.20 & 26.110 & 4095.4 & 14.065 & 340 & 18.66 & 37.11 & 5196.6 & 21.82 \\
\hline 350 & 17.28 & 26.610 & 4267.8 & 14.416 & 350 & 18.68 & 37.65 & 5383.2 & 22.27 \\
\hline 273.15 & 16.41 & 22.43 & 2970 & 11.555 & 273.15 & 18.49 & 33.03 & 3952 & 18.565 \\
\hline 298.15 & 16.75 & 23.88 & 3384 & 12.528 & 298.15 & 18.61 & 34.66 & 4416 & 19.847 \\
\hline
\end{tabular}

a Units: calorie, mole, degree Kelvin.

smoothly interpolated over the range $25-65^{\circ} \mathrm{K}$ and the noncooperative heat capacities calculated from them. By this procedure, the entropy and enthalpy of transition are found to be $\Delta S t=0.71 \mathrm{cal} / \mathrm{mole} \cdot{ }^{\circ} \mathrm{K}$ and $\Delta H t=$ $33 \mathrm{cal} / \mathrm{mole}$ for $\mathrm{MnS}_{2}$ (see Table III). For $\mathrm{MnTe}_{2}$ a similar procedure over the range $54-93^{\circ} \mathrm{K}$ leads to
$\Delta S t=0.55 \mathrm{cal} / \mathrm{mole} \cdot{ }^{\circ} \mathrm{K}$ and $\Delta H t=41 \mathrm{cal} / \mathrm{mole}$ (see Table IV).

The estimated entropy values are only a fraction of the value $R \ln 6=3.56 \mathrm{cal} / \mathrm{mole} \cdot{ }^{\circ} \mathrm{K}$ expected for randomization of the manganese $3 d$ electrons over the state ${ }^{6} S_{5 / 2}$ and indicate that some of the levels are 


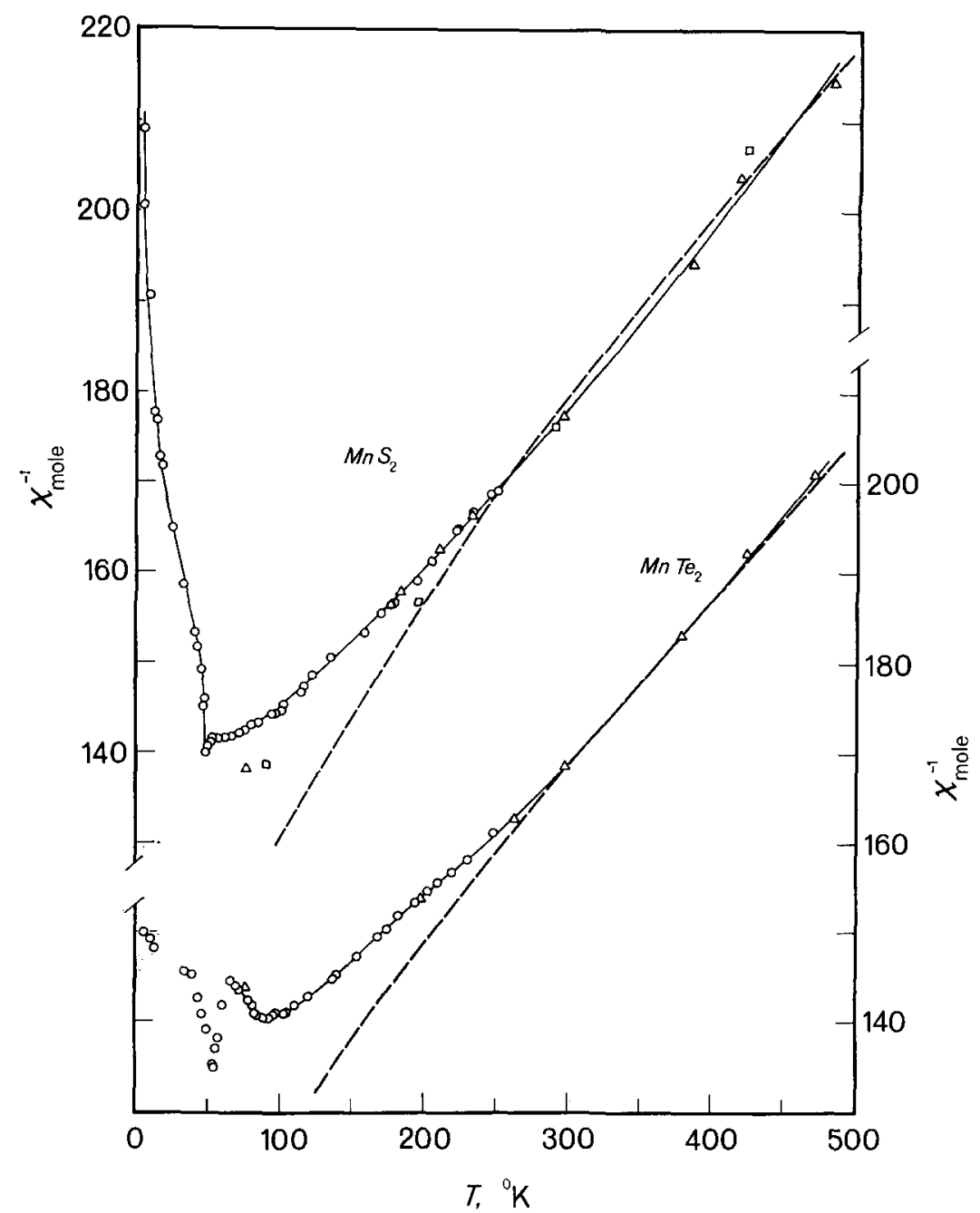

Frg. 3. Reciporcal molar susceptibilities of $\mathrm{NnS}_{2}$ and $\mathrm{MnTe}_{2}$ (corrected for diamagnetism) vs temperature. $\triangle$ represents data by Haraldsen and Klemm $; \square$ represents data by Hastings e $l$ al..$^{5} ; \mathrm{O}$ represents data by $\operatorname{Lin}^{18}$; - represents experimental data; ... represents calculated data assuming zero-field splitting as indicated in the text.

TABLE III. Enthalpy and entropy of transition of $\mathrm{MnS}_{2}$ (hauerite) . ${ }^{\mathrm{a}}$

\begin{tabular}{|c|c|c|c|c|c|}
\hline $\begin{array}{c}\text { Determinations } \\
\text { designation }\end{array}$ & $\begin{array}{c}\text { No. of } \\
\text { deter- } \\
\text { minations }\end{array}$ & $T_{1}$ & $T_{2}$ & $I_{T_{2}}-H_{T_{1}}$ & $H_{55}-H_{44}$ \\
\hline \multicolumn{6}{|c|}{$\mathrm{MnS}_{2}$ (hauerite) } \\
\hline A (Series II) & 2 & 44.737 & 53.968 & 72.226 & 81.84 \\
\hline B (Series III) & 6 & 43.599 & 50.884 & 62.087 & 81.73 \\
\hline $\mathrm{C}($ Series V) & 1 & 46.098 & 48.785 & 37.460 & $82.05^{b}$ \\
\hline Series V & 12 & 44.988 & 48.806 & 44.045 & 81.70 \\
\hline Series VI & 8 & 46.023 & 48.690 & 37.341 & 81.76 \\
\hline $\mathrm{D}$ (Series VII) & 8 & 46.094 & 53.884 & 63.673 & 81.72 \\
\hline \multirow{2}{*}{\multicolumn{3}{|c|}{ Average value }} & \multirow{2}{*}{\multicolumn{3}{|c|}{$\begin{array}{l}H_{55}^{\circ}-H_{44}{ }^{\circ}=81.8 \\
H_{44}^{\circ}-H_{25}^{\circ}=60.6 \\
H_{65}^{\circ}-H_{55}^{\circ}=60.8\end{array}$}} \\
\hline & & & & & \\
\hline \multicolumn{3}{|c|}{ Noncooperative contribution } & \multicolumn{3}{|c|}{$\begin{array}{l}H_{65}{ }^{\circ}-H_{25}^{\circ}=170.4 \\
\Delta H t=33 \\
\Delta S t=0.71\end{array}$} \\
\hline \multicolumn{6}{|l|}{$T_{t}=47.93^{\circ} \mathrm{K}$} \\
\hline
\end{tabular}


TABLE IV. Enthalpy and entropy of transition of $\mathrm{MnTe}_{2}{ }^{a}$

\begin{tabular}{|c|c|c|c|c|c|}
\hline $\begin{array}{c}\text { Determinations } \\
\text { designation }\end{array}$ & $\begin{array}{l}\text { No. of } \\
\text { runs }\end{array}$ & $T_{1}$ & $T_{2}$ & $H_{T_{2}}-H_{T_{1}}$ & $H_{95}-H_{55}$ \\
\hline Series III & 7 & 51.339 & 95.958 & 647.02 & 592.6 \\
\hline Series IV & 19 & 55.917 & 96.937 & 611.28 & 591.7 \\
\hline A & 1 & 53.687 & 93.060 & 577.64 & 592.0 \\
\hline \multicolumn{3}{|c|}{ Average value } & \multicolumn{3}{|c|}{$I_{95}-H_{55}=592.1$} \\
\hline \multicolumn{3}{|c|}{ Lattice contribution } & \multicolumn{3}{|c|}{$\begin{array}{l}H_{95}-H_{55}=551 \\
\Delta H t=41 \\
\Delta S t=0.55\end{array}$} \\
\hline
\end{tabular}

${ }^{a}$ Units: calorie, mole, degree Kelvin.

occupied only at temperatures far above the transition. This interpretation is supported by the magnetic susceptibility measurements. Data for $\mathrm{MnS}_{2}$ by Lin, ${ }^{18}$ Haraldsen and Klemm, ${ }^{4}$ and Hastings et al. ${ }^{5}$ show a Weiss constant of about $600^{\circ} \mathrm{K}$ which might be explained in terms of a large zero-field splitting of the $\pm \frac{3}{2}$ and especially of the $\pm \frac{5}{2}$ levels from the $\pm \frac{1}{2}$ levels. The observed molar susceptibility data can be fitted by the equation

$\chi_{\mathrm{mole}}=\frac{N \beta^{2} g^{2}}{k T}$

$$
\times\left[\frac{\left(\frac{1}{2}\right)^{2}+\left(\frac{3}{2}\right)^{2} \exp \left(-E_{1} / k T\right)+\left(\frac{5}{2}\right)^{2} \exp \left(-E_{2} / k T\right)}{1+\exp \left(-E_{1} / k T\right)+\exp \left(-E_{2} / k T\right)}\right],
$$

where $E_{1}$ and $E_{2}$ are the energy separations of the excited states from the ground state, $N$ is Avogadro's

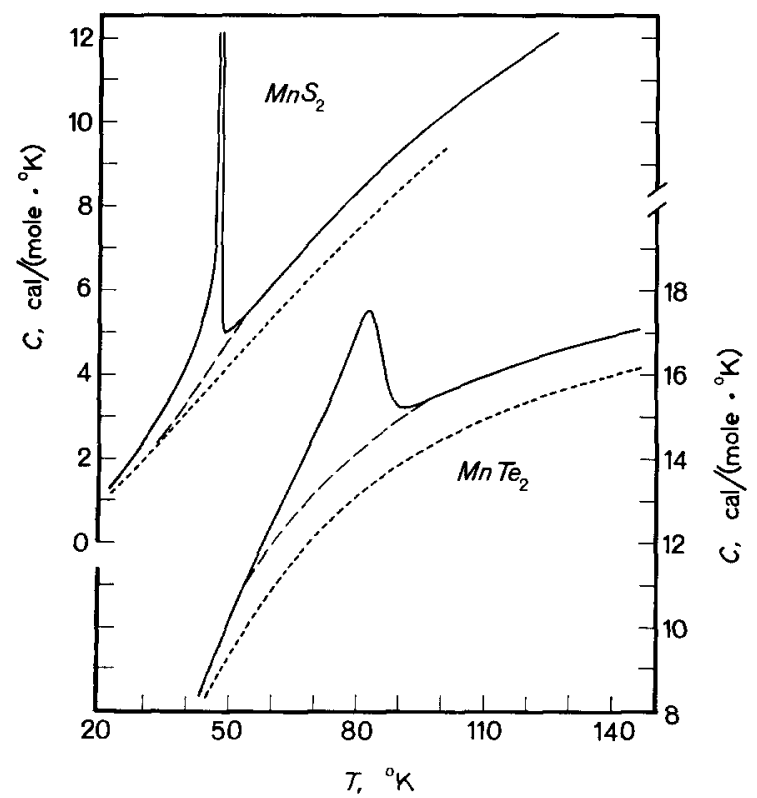

FIg. 4. Heat capacities of $\mathrm{MnS}_{2}$ and $\mathrm{MnTe}_{2}$ in the transition region. - represents experimental data; - - represents estimated lattice heat capacity; - - represents lattice heat capacity plus Schottky contribution. number, $g$ is the Lande factor, $\beta$ is the Bohr magneton, $k$ is Boltzmann's constant, and $T$ is the absolute temperature. As can be seen from Fig. 3, good agreement is obtained with $E_{1} / k=190^{\circ} \mathrm{K}$ and $E_{2} / k=900^{\circ} \mathrm{K}$. According to this picture, the $\lambda$-type transition should involve mainly the $\pm \frac{1}{2}$ states, since the higher ones are slightly populated at the transition temperature, and are not fully excited even at $298^{\circ} \mathrm{K}$. At this temperature, the transitional entropy contribution is $R \ln 6$ minus that for the order persisting at $298^{\circ} \mathrm{K}$, i.e.,

$$
\Delta S t=3.56-0.60=2.96 \mathrm{cal} / \mathrm{mole} \cdot{ }^{\circ} \mathrm{K} .
$$

Separation of the magnetic heat capacity from that of the lattice presupposes knowledge about the phonon dispersion spectrum which, unfortunately, is not yet available. Direct comparison with the structurally related iron compounds is questionable because of the large influence of the number of unpaired $3 d$ electrons on the metal-nonmetal bond distances $(2.59 \mathrm{~A}$ in hauerite and $2.27 \mathrm{~A}$ in pyrite) and thus on the lattice heat capacity. An estimate of the lattice heat capacity can be obtained by subtracting the assumed Schottky contribution from the observed heat capacity in the region above $70^{\circ} \mathrm{K}$ (where the contribution of the $\lambda$-type transition presumably vanishes) and calculating $\theta_{D}$ 's for residual heat capacity. These are joined smoothly with those in the region $10-15^{\circ} \mathrm{K}$ to provide a lattice estimate over the anomalous region. With this tentative lattice contribution (see Fig. 4) a magnetic entropy increment $\Delta S$ at $298^{\circ} \mathrm{K}=2.6 \mathrm{cal} / \mathrm{mole} \cdot{ }^{\circ} \mathrm{K}$ is obtained. Residual contributions from the $\lambda$-type transition above $70^{\circ} \mathrm{K}$ and antiferromagnetic spin waves below $15^{\circ} \mathrm{K}$ would tend to increase this value.

The relative sharpness of the heat capacity maximum in $\mathrm{MnS}_{2}$ poses the question as to whether or not the transition is of first order. It might be answered by the Landau theory of phase transitions, ${ }^{19}$ which puts definite and quite restrictive conditions on the changes in symmetry allowed during a higher-order transition. Dimmock ${ }^{20}$ has discussed these requirements for the magnetic transition in $\mathrm{MnSe}_{2}$ and found that the low-temperature structure cannot transform con- 
tinuously into the pyrite-type structure; for $\mathrm{MnS}_{2}$ and $\mathrm{MnTe}_{2}$ no such restrictions exist. However, even for $\mathrm{MnS}_{2}$, isothermal heat absorption must be small since the enthalpy increment over a $0.04^{\circ} \mathrm{K}$ interval at the maximum is only $3.5 \mathrm{cal} / \mathrm{mole}$. The large naturally occurring single crystals employed may have contributed to the relative sharpness of the transition in comparison with those in other antiferromagnetic substances studied in the form of fine crystalline particles of synthesized samples. X-ray diffraction studies of $\mathrm{MnS}_{2}$ in a cryostat on a horizontal Ge goniometer showed the same profiles of the split $\alpha_{1}$ and $\alpha_{2}$ lines above and below the transition. The structure seemingly remained cubic, with $a=6.096 \mathrm{~A}$ at $4^{\circ} \mathrm{K}$.

For $\mathrm{MnTe}_{2}$ the structure also remains cubic with no indication of deformation on cooling through the transition region. The lattice constant at $4^{\circ} \mathrm{K}$ is $a=6.931 \AA$.

Analysis of the available magnetic susceptibility data by $\mathrm{Lin}^{18}$ and by Hastings et al..$^{5}$ on $\mathrm{MnTe}_{2}$ gives level splittings rather similar to those obtained for $\mathrm{MnS}_{2}$. The reciprocal susceptibility calculated for $E_{1} / k=$ $180^{\circ} \mathrm{K}$ and $E_{2} / k=800^{\circ} \mathrm{K}$ is shown as a function of temperature in Fig. 3 together with the experimental data.

The results indicate, just as for $\mathrm{MnS}_{2}$, that the higher levels are only partially populated at $298^{\circ} \mathrm{K}$. Although the temperature region of the Schottky anomaly is indicated to go below that of the $\lambda$-type transition in Fig. 4, resolution of the two phenomena is probably not feasible in this region. As evidenced by the broadness of the heat capacity maximum, the degree of cooperation is smaller than for $\mathrm{MnS}_{2}$ where the Schottky contribution is less because of higher population of the ground state. Other effects might, however, be asor more-important.

An estimate of the $\mathrm{MnTe}_{2}$ lattice heat capacity was obtained in the same way as for $\mathrm{MnS}_{2}$ by calculating Debye $\theta$ 's outside the transition region after subtracting the assumed Schottky contribution from the observed heat capacity above the $\lambda$ transition (see Fig. 4). The resulting transitional contribution to the entropy at $298^{\circ} \mathrm{K}$ is then $\Delta S t=2.4 \mathrm{cal} / \mathrm{mole} \cdot{ }^{\circ} \mathrm{K}$. The entropy not yet acquired in the Schottky transition is $0.60 \mathrm{cal} /$ mole ${ }^{\circ} \mathrm{K}$. Thus, about $85 \%$ of the expected contribution is accounted for. Evaluation of the lattice heat capacity by other more accurate methods (e.g., inelastic neutron scattering) is a desideratum.

\section{ACKNOWLEDGMENTS}

The continued support by the Division of Research of the U.S. Atomic Energy Commission is gratefully acknowledged. The authors wish to thank Dr. Edward J. Olsen of the Chicago Natural History Museum and Dr. Richard Robie of the U.S. Geological Survey for supplying single crystals of hauerite and Drs. Merritt Hougen and Ray Radebaugh who collaborated in making the measurements. We also thank J. L. Nerliens Fond for financial assistance and Dr. J. Tichy and Mrs. Soung-Sik Kim for assistance with some of the calculations.

* Supported in part by the Division of Research of the U.S. Atomic Energy Commission.

1 P. P. Ewald and W. Friedrich, Ann. Phys. 44, 1183 (1914); P. P. Ewald, Physik. Z. 15, 399 (1914).

${ }^{2}$ I. Oftedal, Z. Physik. Chem. 135, 291 (1928)

${ }_{3}^{3}$ N. Elliott, J. Am. Chem. Soc. 59, 1958 (1937).

${ }^{4} \mathrm{H}$. Haraldsen and W. Klemm, Z. Anorg. Allgem. Chem. 223, 409 (1935).

${ }_{5}^{5}$ J. M. Hastings, N. Elliott, and L. M. Corliss, Phys. Rev. 115, 13 (1959); see also J. Appl. Phys. 29, 392 (1958); H. Haraldsen, "Die Chalkogenide der Ubergangselemente" in Experientia Supplementum VII, XVIth International Congress of Pure and Applied Chemistry, Paris, 1957 (Birkhäuser Verlag, Basel, 1957), pp. 165-82

${ }_{6}^{6}$ L. M. Corliss and J. M. Hastings J. Phys. (Paris) 25, 557 (1964).

${ }^{7}$ L. Neél, Ann. Phys. 3, 137 (1948); see also J. S. Smart, Effective Field Theories of Magnetism (W. B. Saunders, Co., Philadelphia, Pa., 1966).

8 P. W. Anderson, Phys. Rev. 79, 705 (1950).

${ }^{9}$ Values by earlier investigators expressed in $\mathrm{kX}$ units have been transformed to angstroms by multiplication by the factor 1.00202 .

${ }^{10}$ F. Offner, Z. Krist. 89, 182 (1934); see also L. Pauling and M. L. Huggins, ibid. 87, 205 (1934).

${ }^{11}$ W. Biltz and F. Wiechmann, Z. Anorg. Allgem. Chem. 228, 268 (1936).

${ }_{12}$ R. B. Gordon, Am. Mineralogist 36, 918 (1951).

${ }^{13} \mathrm{~S}$. Furuseth and A. Kjekshus, Acta Chem. Scand. 19, 1405 (1965).

${ }_{14} \mathrm{~S}$. Furberg, Acta Chem. Scand. 7, 693 (1953).

${ }_{15}$ A. Sawoka and S. Miyhara, J. Phys. Soc. Japan 20, 2087 (1965).

${ }^{16}$ E. F. Westrum, Jr., J. Chem. Educ. 39, 443 (1962).

${ }^{17} \mathrm{~B}$. H. Justice, doctoral dissertation, University of Michigan, Ann Arbor, Mich., 1961. U.S.A.E.C. Rept. TID-12722, 1961.

${ }^{18}$ M. S. Lin, "A study on the Antiferromagnetic Transitions of Three Ionic Compounds at Low Temperatures," dissertation, University of Michigan Ann Arbor, Mich, 1964; Dissertation Abstr. 25, 7159 (1965) .

${ }_{19}$ L. Landau, Phys. Z. Sowjet. 11, 26, 545 (1937) ; Collected Papers of L. D. Landau (Gordon and Breach Science Publishers, Inc., New York, 1967), p. 193; L. D. Landau and E. M. Lifshitz, Statistical Physics (Pergamon Press, Inc., New York, 1958).

${ }^{20}$ J. O. Dimmock, Phys. Rev. 130, 1334 (1964). 